\title{
RARE EARTH ELEMENTS COMPLEXATION WITH HUMIC ACID
}

Olivier Pourret*, Mélanie Davranche, Gérard Gruau, Aline Dia

Géosciences Rennes - UMR CNRS 6118

Université Rennes 1 - Campus de Beaulieu

35042 Rennes Cédex, France

\footnotetext{
* Corresponding author: tel.: 332232360 42; fax: 332232360 90; e-mail address: olivier.pourret@univrennes1.fr.
} 


\begin{abstract}
The binding of rare earth elements (REE) to humic acid (HA) was studied
\end{abstract} by combining Ultrafiltration and Inductively Coupled Plasma Mass Spectrometry techniques. REE-HA complexation experiments were performed at various $\mathrm{pH}$ conditions (ranging from 2 to 10.5) using a standard batch equilibration method. Results show that the amount of REE bound to HA strongly increase with increasing $\mathrm{pH}$. Moreover, a Middle REE (MREE) downward concavity is evidenced by REE distribution patterns at acidic $\mathrm{pH}$. Modelling of the experimental data using Humic Ion Binding Model VI provided a set of log $\mathrm{K}_{\mathrm{MA}}$ values (i.e., the REE-HA complexation constants specific to Model VI) for the entire REE series. The log $\mathrm{K}_{\mathrm{MA}}$ pattern obtained displays a MREE downward concavity. Log $\mathrm{K}_{\mathrm{MA}}$ values range from 2.42 to 2.79 . These binding constants are in good agreement with the few existing datasets quantifying the binding of REE with humic substances but quite different from a recently published study which evidence a lanthanide contraction effect (i.e., continuous increase of the constant from La to $\mathrm{Lu}$ ). The MREE downward concavity displayed by REE-HA complexation pattern determined in this study compares well with results from REE-fulvic acid (FA) and REE-acetic acid complexation studies. This similarity in the REE complexation pattern suggests that carboxylic groups are the main binding sites of REE in HA. This conclusion is further illustrated by a detailed review of published studies for natural, organic-rich, river- and ground-waters which show no evidence of a lanthanide contraction effect in REE pattern. Finally, application of Model VI using the new, experimentally determined log $\mathrm{K}_{\mathrm{MA}}$ values to World Average River Water confirms earlier suggestions that REE occur predominantly as organic complexes $(\geq 60 \%)$ in the $\mathrm{pH}$ range between 5-5.5 and 7-8.5 (i.e., in circumneutral $\mathrm{pH}$ waters). The only significant difference as compared to earlier model predictions made using estimated $\log \mathrm{K}_{\mathrm{MA}}$ values is that the experimentally determined $\log \mathrm{K}_{\mathrm{MA}}$ values predict a significantly higher amount of Light REE bound to organic matter under alkaline $\mathrm{pH}$ conditions. 
Keywords: Rare earth elements, humic acid, binding, speciation, ultrafiltration, Model VI 


\section{Introduction}

Rare Earth Elements (REE) are commonly used as tracers for geochemical processes in natural waters (Elderfield and Greaves, 1982; Henderson, 1984; Elderfield et al., 1990; Smedley, 1991; Sholkovitz, 1995; Johannesson et al., 1997; Johannesson et al., 2000). Ground- and river-waters do not exhibit uniform REE patterns (Goldstein and Jacobsen, 1988; Elderfield et al., 1990; Sholkovitz, 1995). Systematic variations in REE patterns occur which have been attributed, in part, to the presence of two REE pools - so-called "dissolved" and "colloidal" pools - having different REE fractionation pattern. For example, it is often suggested that REE patterns of rivers result from the mixing between (i) a low REE concentration, dissolved pool, Light-REE (LREE) depleted, but Heavy-REE (HREE) enriched related to Upper Continental Crust (UCC) (Taylor and McLennan, 1985) and (ii) a REE-rich colloidal phase having a Middle-REE (MREE) downward concavity pattern, namely a pattern that exhibits both $(\mathrm{La} / \mathrm{Sm})_{\mathrm{UCC}}$ ratio below 1 and $(\mathrm{Gd} / \mathrm{Yb})_{\mathrm{UCC}}$ ratio above 1 (Goldstein and Jacobsen, 1988; Elderfield et al., 1990; Sholkovitz, 1995). Humic substances constitute a significant part of the colloidal phase in both ground- and river-waters (Thurman, 1985). Consequently, interpreting and understanding the significance of REE fractionation pattern variability in these waters rely, for a large part, on a better description of the binding of REE to humic materials (HM) and of the REE fractionation patterns that may occur during this binding.

Models based on thermodynamics principles offer an interesting perspective in order to predict the complexation of REE with HM and thus to explore the extent to which the shape of ground- and river-water REE patterns depends on REE fractionation by HM. Modelling calculations were already performed in seawater (Cantrell and Byrne, 1987; Byrne and Kim, 1990; De Baar et al., 1991) and groundwaters (Wood, 1990; Lee and Byrne, 1992; 
Johannesson et al., 1996b). They evidence that hydroxides and carbonates (Cantrell and Byrne, 1987; Lee and Byrne, 1993; Liu and Byrne, 1998; Luo and Byrne, 2004) are the major inorganic complexing ligands of REE. However, organic complexation is often not taken into account in these calculations. Studies on REE - dissolved organic material (DOM) interactions and in particular humic and fulvic acids (HA and FA) are sparse in all respect (Dupré et al., 1999; Tang and Johannesson, 2003; Johannesson et al., 2004). Natural organic molecules contain numerous and chemically different binding sites, and thus it is difficult to define discrete equilibrium constants for each complexation reaction (Crawford, 1996). Thus, addressing complexation with DOM in existing aqueous speciation models is not obvious. Until recently, REE-FA or -HA complexation constants were generally determined for a single REE (e.g., for HA: Sm-HA, Eu-HA, Tb-HA and Dy-HA) (Maes et al., 1988; Bidoglio et al., 1991; Moulin et al., 1992; Dierckx et al., 1994; Fairhurst et al., 1995; Franz et al., 1997; Lead et al., 1998; Lippold et al., 2005) or a set of REE (Ce, Eu, Gd, Tm and Lu) (Takahashi et al., 1997) while accurate stability constants are needed for the 14 naturally occurring REE to model speciation of natural water. Only two studies reporting REE-humate binding constants for the 14 naturally occurring REE have been so far published. They have unfortunately yielded to somewhat different results. Yamamoto et al. $(2005,2006)$ studied complexation of REE with Suwannee River FA (SRFA) and Suwannee River HA (SRHA) using a solvent extraction method. Patterns of REE-FA and REE-HA complexation constants obtained by these authors show a general MREE downward concavity similar to that obtained for REEdiacetic acid complexation, sometimes superimposed to an overall increase of complexation constants from LREE to HREE. By contrast, Sonke and Salters (2006) studied complexation of REE with SRFA, Leonardite coal HA (LHA) and Elliot soil HA (EHA) using an EDTAligand competition method. Complexation patterns obtained by these authors are quite different from those reported by Yamamoto et al. (2005) exhibiting a lanthanide contraction 
effect, i.e., a regular and progressive increase of the constants from $\mathrm{La}$ to $\mathrm{Lu}$. It must be added that experimental $\mathrm{pH}$ range are different in both of these studies ranging between 4 and 5.5 in Yamamoto et al. studies (2005; 2006) and 6 and 9 in Sonke and Salters' one (2006).

In this contribution, in order to further test evidences provided by both studies (Yamamoto et al., 2005; Sonke and Salters, 2006) and provide a more accurate REE-HA complexation dataset, experiments of REE-Aldrich HA (AHA) complexation were performed for the 14 naturally occurring REE simultaneously. This new dataset was obtained using a third experimental method which combines an ultrafiltration technique and the Inductively Coupled Plasma Mass Spectrometry method. Humic Ion Binding Model VI (hereafter denoted as Model VI) was used to model the experimental results (Tipping, 1998). Therefore, the constants reported are not intrinsic equilibrium constants but Model VI specific equilibrium constants (i.e., log $\mathrm{K}_{\mathrm{MA}}$ values). Considering the key role played by organic colloids in natural terrestrial waters, the new results were also used to revisit the significance of REE patterns in organic-rich, ground- and river-waters. Finally, the new constants were input in Model VI to reinvestigate World Average River Water (Tang and Johannesson, 2003) and further constrain the speciation of REE in river waters.

\section{Materials and Method}

\subsection{Experimental Binding of Rare Earth Elements by Humic Acid}

All chemicals used in this study were of analytical grade, and all the experimental solutions used prepared with doubly deionized water (MilliQ system, Millipore ${ }^{\mathrm{TM}}$ ). REE-HA complexes were prepared in polyethylene containers previously soaked in $10 \%$ Ultrapure $\mathrm{HNO}_{3}$ for $48 \mathrm{~h}$ at $60{ }^{\circ} \mathrm{C}$, then rinsed with MilliQ water for $24 \mathrm{~h}$ at $60{ }^{\circ} \mathrm{C}$ to remove all 
possible REE contamination sources. Synthetic REE solutions were prepared from nitrate REE standards (10 ppm, Accu Trace ${ }^{\mathrm{TM}}$ Reference Standard). All experiments were carried out at room temperature, i.e., $20{ }^{\circ} \mathrm{C} \pm 2$.

\subsubsection{Humic acid}

Purified humate, referred to below as HA (humic acid), was obtained from synthetic Aldrich $^{\mathrm{TM}}$ humic acid (Aldrich $\left.{ }^{\mathrm{TM}}, \mathrm{H} 1,675-2\right)$ following the protocol described by Vermeer et al. (Vermeer et al., 1998). HA sample was freeze-dried and stored in a glass container at room temperature. HA obtained was ash free and in its protonated form, with the following elemental composition (as mass fraction): $\mathrm{C}=55.8 \%, \mathrm{O}=38.9 \%, \mathrm{H}=4.6 \%, \mathrm{~N}=0.6 \%$. REE concentrations in HA were below the detection limit of ICP-MS measurement (i.e., $<1$ ppt). HA has a mean molecular weight of $23 \mathrm{kDa}$ (Vermeer et al., 1998). Prior to use, the freeze-dried humate was resuspended overnight in an $0.001 \mathrm{~mol} \mathrm{~L}^{-1} \mathrm{NaCl}$ electrolyte solution at $\mathrm{pH}=10$, to ensure complete dissolution of the sample (Davranche et al., 2004; Davranche et al., 2005). Although AHA is sometimes criticized as a weak model for humic substances (HS), its ion-binding behavior and physico-chemical properties are rather similar to those of other HS (Avena et al., 1999; Milne et al., 2001; 2003; Saito et al., 2005).

\subsubsection{Experimental set-up description}

REE complexation with HA was investigated using a standard batch equilibration technique.

REE (50 ppb of each REE) and HA (5, 10 and $20 \mathrm{mg} \mathrm{L}^{-1}$ ) were placed together in solution, at an ionic strength of $0.001 \mathrm{~mol} \mathrm{~L}^{-1}$ and at $\mathrm{pH}$ values ranging from 2.18 to 10.44 . Prior to addition of HA, pH-solution was about 4. The initial hydroxide and carbonate concentrations were thus negligible and concentrations of $\mathrm{LnOH}^{2+}$ and $\mathrm{LnCO}_{3}{ }^{2-}$ were therefore also negligible. The $\mathrm{pH}$ was measured with a combined Radiometer Red Rod electrode. 
The electrode was calibrated with WTW standard solutions ( $\mathrm{pH} 4,7$ and 10). The accuracy of the $\mathrm{pH}$ measurement was $\pm 0.05 \mathrm{pH}$ unit. Experimental solutions were stirred for $48 \mathrm{~h}$ (equilibrium time determined from preliminary kinetic experiments) to allow equilibration and partitioning of REE between the aqueous solution and the humate suspension. Solution aliquots of about $10 \mathrm{~mL}$ were sampled twice: first at the beginning of the experiment; then after $48 \mathrm{~h}$ at equilibrium state. REE complexed by the HA were separated from the remaining inorganic REE by ultrafiltration. Ultrafiltrations were carried out by centrifugating the $10 \mathrm{~mL}$ solution samples through $15 \mathrm{~mL}$ centrifugal tubes equipped with permeable membranes of $5 \mathrm{kDa}$ pore size (Millipore Amicon Ultra-15). All centrifugal filter devices used were washed and rinsed with $0.1 \mathrm{~mol} \mathrm{~L}^{-1} \mathrm{HCl}$ and MilliQ water two times before use in order to minimize contamination. Centrifugations were performed using a Jouan G4.12 centrifuge with swinging bucket rotor at $3000 \mathrm{~g}$ for 30 minutes. The centrifugal force allowed the REE-HA complexes to be quantitatively separated from inorganic REE species. The used membrane can retain the humic material, while permitting passage of smaller solutes. REEHA complexes have a mean molecular weight of $23 \mathrm{kDa}$, and are therefore caught up by the 5 $\mathrm{kDa}$ membrane whereas inorganic REE species went through it. The filtrate contains only the free REE, while the retentate contains HA and associate bound REE. The amount of metal bound is determined by difference. The selectivity of the $5 \mathrm{kDa}$ membrane regards to the REE-HA complexes was verified by monitoring the Dissolved Organic Carbon (DOC) contents of the ultrafiltrates. Results show that the latter were systematically lower or equal to blank values $(\leq 0.1 \mathrm{ppm})$. Even if the passage of small amounts of low molecular weight FA through the ultrafiltration membrane was previously described (Nordén et al., 1993) in such measurement of metal binding by HS, we considered that the purified HA ( $23 \mathrm{kDa})$ could not pass through the membrane $(5 \mathrm{kDa})$ as illustrated by ultrafiltrate DOC values lower or equal to blank ones. Possible adsorption of inorganic REE species onto the membrane or onto cell 
walls was also monitored. Inorganic REE solutions of known REE concentration were ultrafiltered several times. Results showed that between 98.91 (for Ho) and $99.98 \%$ (for $\mathrm{Yb}$ ) of the REE present in solution were recovered in the ultrafiltrates, demonstrating that no REE was adsorbed on the membranes nor on the walls of the cell devices used.

In the following, REE complexation with HA is described by quantifying the amount of $\mathrm{REE}$ that remains into the $<5 \mathrm{kDa}$ ultrafiltrates after equilibration of the REE-bearing aqueous solutions with HA and by comparing this amount to the amount of REE which has been introduced initially into the experimental solutions. All the removed REE are assumed to have been complexed by the $23 \mathrm{kDa} \mathrm{HA}$. REE concentrations were determined at Rennes 1 University using an Agilent Technologies ${ }^{\mathrm{TM}}$ HP4500 ICP-MS instrument. Quantitative analyses were performed using a conventional external calibration procedure. Three external standard solutions with REE concentrations similar to the analyzed samples were prepared from a multi-REE standard solution (Accu Trace ${ }^{\mathrm{TM}}$ Reference, $10 \mathrm{mg} \mathrm{L}^{-1}$, USA). Indium was added to all samples as an internal standard at a concentration of $0.87 \mu \mathrm{mol} \mathrm{L} \mathrm{L}^{-1}(100 \mathrm{ppb})$ to correct for instrumental drift and possible matrix effects. Indium was also added to the external standard solutions. Calibration curves were calculated from measured REE/indium intensity ratios. The accuracy on REE analysis in our laboratory as established from repeated analyses of multi-REE standard solution (Accu Trace ${ }^{\mathrm{TM}}$ Reference, USA) and of the SLRS-4 water standard is $< \pm 2.5 \%$ (Dia et al., 2000; Davranche et al., 2005). Chemical blanks of individual REE were all lower than detection limit (1 ppt), which is negligible since they are three to four orders of magnitude lower than the concentrations measured in the synthetic solutions used in the complexation experiments. DOC concentrations were determined at Rennes 1 University using a Shimadzu 5000 TOC analyzer. The accuracy of DOC concentration measurements is estimated at $\pm 5 \%$ as determined by repeated analyses of freshly prepared standard solutions (potassium biphtalate). In order to check that no retention 
of REE occurs inside the membrane during ultrafiltration, mass balance calculations were performed. The initial concentration of each element is compared with the sum of each element concentration in the ultrafiltrate and in the retentate. In the presented experiments, mass balanced calculations show that $>98 \%$ of the REE and DOC were recovered. Moreover, in order to verify that no precipitation occurs, samples were filtered at $0.2 \mu \mathrm{m}$ before ultrafiltration. Concentrations of REE and HA were systematically identical within analytical uncertainties in the $0.2 \mu \mathrm{m}$ filtrates and the raw samples.

\subsection{Humic Ion Binding Model VI}

Humic Ion Binding Model VI (Model VI) has been described in detail by Tipping (Tipping, 1998). The model is a discrete binding site model which takes into account electrostatic interactions. There is an empirical relation between net humic charge and an electrostatic interaction factor. The discrete binding sites are represented by two types of sites (types A and B), each comprising four different site subtypes present in equal amounts. Types $\mathrm{A}$ and $\mathrm{B}$ sites are described by intrinsic proton binding constants $\left(\mathrm{pK}_{\mathrm{A}}\right.$ and $\left.\mathrm{pK} \mathrm{B}_{\mathrm{B}}\right)$ and spreads of the values $\left(\Delta \mathrm{pK}_{\mathrm{A}}\right.$ and $\left.\Delta \mathrm{pK}_{\mathrm{B}}\right)$ within each type. There are $\mathrm{n}_{\mathrm{A}}\left(\mathrm{mol} \mathrm{g}^{-1}\right)$ Type A sites (associated with carboxylic type groups) and $n_{B}=n_{A} / 2\left(m o l ~ g^{-1}\right)$ Type $B$ sites (often associated with phenolic type groups). Metal binding occurs at single proton binding sites (monodentate complexation) or by bidentate complexation between pairs of sites. A proximity factor is introduced that quantifies whether pairs of proton binding groups are close enough to form bidentate sites. Type A and Type B sites have separate intrinsic binding constants (log $\mathrm{K}_{\mathrm{MA}}$ and $\log \mathrm{K}_{\mathrm{MB}}$ ), together associated with a parameter, $\Delta \mathrm{LK}_{1}$, defining the spreads of values around the medians. A further parameter, $\Delta \mathrm{LK}_{2}$, takes into account a small number of stronger sites (bidentate and tridentate sites). For more details on whether mono-, bi and 
tridentate sites may form see Tipping (1998). By considering results from many datasets, a universal average value of $\Delta \mathrm{LK}_{1}$ is obtained, and a correlation established between $\log \mathrm{K}_{\mathrm{MB}}$ and $\log \mathrm{K}_{\mathrm{MA}}$ (Tipping, 1998). Then, a single adjustable parameter $\left(\log \mathrm{K}_{\mathrm{MA}}\right)$ is necessary to fully describe metal complexation with HA in Model VI. Model VI parameters for HA are presented in Table 1 . Model VI was preferentially selected because this model is a widely accepted metal-organic matter speciation code whose capability to model Eu complexation with HM has been already tested and proved to perform reasonably well (Lead et al., 1998). Binding of the first hydrolysis species $\operatorname{REE}(\mathrm{OH})$ to humics was not included in Model VI simulations.

Location of Table 1.

\section{Results}

\subsection{Experimental results}

Experimental data are reported in Appendix A and illustrated for three REE (La, Eu, Lu) in Fig. 1. REE complexation by HA is examined by considering the proportion of REEHA complexes formed as a function of $\mathrm{pH}$. As shown in Fig. 1, the proportion of REE-HA complexes increases with increasing $\mathrm{pH}$. It also depends on the HA concentration of the experimental solution. More specifically, the $\mathrm{pH}$ at which $100 \%$ of the REE are complexed by HA decreases with increasing HA concentration: $\mathrm{pH} \approx 4,5.5$ and 7 for HA concentrations of 20,10 and $5 \mathrm{mg} \mathrm{L}^{-1}$, respectively (see Fig. 1). These results are in good agreement with previously published data (Maes et al., 1988; Dierckx et al., 1994; Franz et al., 1997; Lippold et al., 2005). The observed pH-dependence of REE complexation by HA can be explained by the de-protonation of the HA carboxylic and phenolic surface groups at increasing $\mathrm{pH}$, which 
is a classical feature of metal ion complexation by humic acid (Fairhurst et al., 1995; Lippold et al., 2005). Interestingly, patterns of the proportions of REE-HA exhibits a MREE downward concavity (i.e., (La-HA)/(Sm-HA) $<1$ and $(\mathrm{Gd}-\mathrm{HA}) /(\mathrm{Yb}-\mathrm{HA})>1)$ when the amount of REE complexed with HA is sufficiently low to evidence possible fractionation among the REE series (i.e., under acidic pH conditions; Fig. 2 and Appendix A). The same feature was already observed in complexation experiments of the REE with AHA using the dialysis method (Davranche et al., 2005).

Location of Fig. 1 and Fig. 2.

\subsection{Calculating $\log K_{M A}$ values}

Calculations were performed using the computer program WHAM 6 (Version 6.0.13) which includes Model VI. The three datasets corresponding to the three different HA concentrations used were separately modelled. A classical strategy that consists in adjusting $\log \mathrm{K}_{\mathrm{MA}}$ for each REE simultaneously until a reasonable fit is achieved was used. Values of $\left[\mathrm{REE}^{3+}\right]$ (i.e., the concentration of REE left in the $<5 \mathrm{kDa}$ ultrafiltrates) and $v$ (moles of REE bound per gram of humic acid; i.e., the difference between the concentration of REE left in the $<5 \mathrm{kDa}$ ultrafiltrates and the concentration of REE initially present in the experimental solutions) are derived from the experimental data. The best fit is obtained when the root mean square error of the regression (rmse $=$ sum of the squares of the differences between observed and calculated $\log v$ ) is minimised. The three sets of optimised $\log \mathrm{K}_{\mathrm{MA}}$ values thus obtained are reported in Table 2 for the 14 analyzed REE and illustrated in Fig. 3 for the case of La. As indicated by rmse values $(<0.07)$, fits could be considered of good quality. The main characteristics of the REE-HA experiments to be reproduced by Model VI are a high proportion of REE-HA complexes at relatively low $\mathrm{pH}$ and a marked increase of this 
proportion with increasing $\mathrm{pH}$. Log $\mathrm{K}_{\mathrm{MA}}$ values increase with $\mathrm{HA}$ concentration of experimental solutions. The overall difference is of ca. 0.3 for all REE, which corresponds to a difference of ca. $12 \%$ on estimated $\log \mathrm{K}_{\mathrm{MA}}$ values. As can be seen in Fig. 3, a $12 \%$ difference on $\log \mathrm{K}_{\mathrm{MA}}$ values may result in a difference of up to $20 \%$ on the calculated proportion of REE-HA complex if the $\mathrm{pH}$ and the HA concentration are low. The default value is computed by taking the mean between the three sets of values. This procedures means that equal weight is given to all the data sets obtained for different HA concentration levels. It implies that differences in $\log \mathrm{K}_{\mathrm{MA}}$ for a given type of humic material are due to variations from one sample to another (Tipping, 1998). The adopted values are listed in Table 2. Log $\mathrm{K}_{\mathrm{MA}}$ values increase from $\mathrm{La}(2.58)$ to $\mathrm{Eu}$ (2.65), then decrease from $\mathrm{Gd}$ (2.63) to $\mathrm{Lu}$ (2.59). It follows a $\log \mathrm{K}_{\mathrm{MA}}$ pattern showing a MREE downward concavity.

Location of Fig. 3 and Table 2.

\section{Discussion}

\subsection{Comparison with published results}

Data from previous studies (Moulin et al., 1992; Fairhurst et al., 1995; Lippold et al., 2005; Sonke and Salters, 2006) were modelled using Model VI to compare them with the newly obtained set of $\log \mathrm{K}_{\mathrm{MA}}$. Previous studies (Moulin et al., 1992; Fairhurst et al., 1995; Lippold et al., 2005) provide data for only a limited number of REE, namely $\mathrm{Tb}$, Dy and Eu. Experimental conditions and fit results for these three studies are presented in Table 3. Modelled $\log \mathrm{K}_{\mathrm{MA}}$ values for $\mathrm{Tb}$ (2.57) and $\mathrm{Eu}$ (2.73 and 2.77) are within the error range of the average $\log \mathrm{K}_{\mathrm{MA}}$ values obtained here for these two REE $(2.62 \pm 0.16$ and $2.65 \pm 0.15$, respectively; see Table 2). Only results for Dy are statistically different: 3.19 against $2.61 \pm$ 
0.16 in the present study. The present results have also been compared to recently published results for the complexation of the 14 naturally occurring REE by Leonardite HA (LHA), a coal derived HA (Sonke and Salters, 2006). Complexation of the REE by LHA was experimentally studied at four different $\mathrm{pH}(6,7,8$ and 9) using an EDTA-ligand competition method (Sonke and Salters, 2006). The corresponding modelled log $\mathrm{K}_{\mathrm{MA}}$ values are reported in Table 4. Even if $\log \mathrm{K}_{\mathrm{MA}}$ values calculated for the LHA are of the same order of magnitude than $\log \mathrm{K}_{\mathrm{MA}}$ values calculated for the AHA, a marked difference is noted in the REE fractionation pattern of $\log \mathrm{K}_{\mathrm{MA}}$ values. REE-LHA complexation constants do not evidence the same MREE downward concavity as compared to that obtained with AHA, showing instead a progressive and continuous increase of $\log \mathrm{K}_{\mathrm{MA}}$ values from $\mathrm{La}$ to $\mathrm{Lu}$ (i.e., $\log$ $\mathrm{K}_{\mathrm{MA}}(\mathrm{La}-\mathrm{HA}) / \log \mathrm{K}_{\mathrm{MA}}(\mathrm{Sm}-\mathrm{HA})<1$ and $\left.\log \mathrm{K}_{\mathrm{MA}}(\mathrm{Gd}-\mathrm{HA}) / \log \mathrm{K}_{\mathrm{MA}}(\mathrm{Yb}-\mathrm{HA})<1\right)$. This continuous increase of $\log \mathrm{K}_{\mathrm{MA}}$ values from $\mathrm{La}$ to $\mathrm{Lu}$ as obtained for the LHA has been ascribed to a lanthanide contraction effect, and is quantified as the numerical difference between the Lu and La binding constants ( $\Delta_{\mathrm{L}} \beta_{\mathrm{Lu}-\mathrm{La}}$ in Sonke and Salters, 2006). Such a feature (i.e., lanthanide contraction) have already been attributed to REE binding to coal derived HA (Takahashi et al., 1997).

Location of Table 3 and Table 4.

The major difference between the results obtained here and the only dataset so far published for the 14 naturally occurring REE with HA is thus in the shape of the log $\mathrm{K}_{\mathrm{MA}}$ values: MREE downward concavity here against linear increase from $\mathrm{La}$ to $\mathrm{Lu}$ for data published by Sonke and Salters (2006). They compared the constants they found for REELHA complexation with those found for 101 organic ligands (Byrne and Li, 1995). They further suggested that the lanthanide contraction effect they observed for LHA was in fact shared by a large number of organic ligands and could thus be a general feature of REE complexation by organic compounds. In addition to LHA, Sonke and Salters (2006) also 
determined REE complexation constants for two other HM sources - namely, fulvic acid from the Suwannee River and Elliot soil humic acid - using the same ligand-ligand technique as that used for LHA. They also evidenced a lanthanide contraction effect of their constant pattern. In the present study, no observation was found that a lanthanide contraction effect should exist in the complexation constants of REE by organic matter. Instead, the existing databank (Wood, 1993; Byrne and Li, 1995) points out that a MREE downward concavity of some constant pattern could occurred, as obtained in the present study.

Location of Fig. 4.

Complexation constants of REE with SRFA and SRHA were also determined by Yamamoto et al. $(2005,2006)$ using a solvent extraction technique (Fig. 4a; see also Fig. 1 in Yamamoto et al., 2005). Pattern of $\log \beta$ (REE-FA) and $\log \beta$ (REE-HA) looks very much like that found in the present study for REE-HA, being characterized by a MREE downward concavity shape (i.e., $\log \mathrm{K}_{\mathrm{MA}}(\mathrm{La}-\mathrm{HA}) / \log \mathrm{K}_{\mathrm{MA}}(\mathrm{Sm}-\mathrm{HA})<1$ and $\log \mathrm{K}_{\mathrm{MA}}(\mathrm{Gd}-\mathrm{HA}) / \log$ $\left.\mathrm{K}_{\mathrm{MA}}(\mathrm{Yb}-\mathrm{HA})>1\right)$. Binding of the REE to humic substances occurs mainly through carboxylic functions (Yamamoto et al., 2005). In this respect, simple organic compounds possessing carboxylic functional groups such as acetate can be regarded as analogue of complex organic matter, such as HA and FA (Wood, 1993). Thus, log $\mathrm{K}_{\mathrm{MA}}$ pattern of REE complexation with FA, HA and acetic acid can be together compared (Fig. 4) (Wood, 1993; Byrne and Li, 1995). As can be seen, patterns of log $\mathrm{K}_{\mathrm{MA}}$ values for acetic and diacetic acids do not evidence a lanthanide contraction effect: they are MREE downward concave, mimicking both those obtained by Yamamoto et al. $(2005,2006)$ for SRFA and SRHA and through this study for AHA. However, in some sample (particularly at pH 5.38) log $\beta$ (REEFA) show both a MREE downward concavity superimposed on an overall increase in $\log \beta$ (REE-FA) from LREE to HREE (Yamamoto et al. 2006).

Location of Fig. 5. 
The argument used by Sonke and Salters (2006) that a lanthanide contraction effect is observed in the constant pattern of many organic compounds is questionable. Indeed, their demonstration was built on the fact that a positive correlation exists when $\Delta_{\mathrm{L}} \beta_{\mathrm{Lu}-\mathrm{La}}$ of organic compounds is plotted against the average REE constant $\left(\beta_{\text {ave }}\right)$. REE stability constant is not always a simple function of atomic number. As suggested by Byrne and Li (1995), REE are best viewed as two series of elements corresponding to the LREE and HREE groups. The REE patterns of complexation constants with many organic ligands (Wood, 1993; Byrne and $\mathrm{Li}, 1995)$ or some inorganic ligands like $\mathrm{NO}_{3}{ }^{-}$(Wood, 1990; Millero, 1992) are characterized by a downward concavity centred on MREE. This shape corresponds to a $(\mathrm{La} / \mathrm{Sm})$ ratio below 1 and $(\mathrm{Gd} / \mathrm{Yb})$ ratio above 1 (Fig. 4a). Thus, such shapes are best viewed when REE are considered as two subgroups. Indeed, $(\mathrm{La} / \mathrm{Lu})$ ratio does not give an accurate description of the constants pattern. Let us for example consider a $(\mathrm{La} / \mathrm{Lu})$ ratio $<1$. Such a value may actually reflect a pattern showing a continuous increase of the constant values from $\mathrm{La}$ to $\mathrm{Lu}$, and thus a real lanthanide contraction effect. However, it may also reflect a REE pattern showing an increase of $\log \beta$ values only from $\mathrm{La}$ to $\mathrm{Sm}$ or $\mathrm{Eu}$ and then constant values from Gd to $\mathrm{Lu}$ (no real HREE enrichment). It may even reflect a MREE downward concave pattern, the only required feature in that case being $\log \beta_{\mathrm{La}}<\log \beta_{\mathrm{Lu}}$. To test this possibility $(\mathrm{Gd} / \mathrm{Lu})$ ratios (i.e., shape of the MREE and HREE part of the constant pattern) for the same 101 organic compounds were calculated and compared with $(\mathrm{Gd} / \mathrm{Yb})$ ratios and $\log \beta$ of these compounds. As shown in Fig. 5, the comparison shows that the positive correlation reported by Sonke and Salters (2006) when reporting $(\mathrm{La} / \mathrm{Lu})$ ratios of 101 compounds against their $\beta_{\text {ave }}$ is lost when $(\mathrm{Gd} / \mathrm{Yb})$ is substituted to $(\mathrm{La} / \mathrm{Lu})$ ratios. For the purpose comparison Yamamoto et al. data for SRFA and SRHA (Yamamoto et al., 2005; 2006) and Sonke and Salters' data for SRFA and LHA (2006) were included in Fig. 5. In the present study, preliminary REE-HA constants calculations (not shown) give an order of magnitude for $\log \beta$ 
values. While Yamamoto's $\log \beta$ for SRFA and SRHA and our $\log \beta$ for AHA are in the field of natural carboxylic and phenolic acids (Fig. 5), Sonke and Salters' $\log \beta$ for SRFA and LHA are in the field of natural phenolic acids, natural aminocarboxylic acid and synthetic iminoacetic acids such as EDTA (Fig. 5). Observed differences between experiments presented in this study, and literature data (Takahashi et al., 1997; Yamamoto et al., 2005; Sonke et al., 2006; Yamamoto et al., 2006) strongly suggests the heterogeneity of the complexing site (i.e., the coexistence of weak and strong binding sites) in the humic acid (Kubota et al., 2002). The main features of our observations is that one can interprets differences as due to high concentration of weak sites (acetic-like sites) and low concentrations of strong sites (EDTA-like sites). The weak sites determine the behavior of humic complexation at high metal concentrations, whereas the strong sites, although their concentration is only in the range of a few percent of the weak sites, determine the complexation strength of humic substances at trace metal concentrations (Hummel et al., 1995; Yamamoto et al., 2005). Our study HS/Ln ratios are between 5 and 20, whereas in Yamamoto et al. (2005) experiments they are close to 80, in Sonke and Salters (2005) between 550 and 600 (in LHA experiments) and in Takahashi et al. (1997) as high as 100,000. Such a feature was already observed by Bidoglio et al. (1991) and Moulin et al. (1992) who evidenced that the REE concentration exerts a relatively great effect on the HM complexing capacity. This may be explained by a loading effect: at low loading, stronger sites will be favored whereas at large loadings, weaker sites will be involved in the complexation. This "HS/Ln ratio" effect is further marked by $\mathrm{pH}$ conditions: phenolic sites are predominant at alkaline $\mathrm{pH}$ whereas carboxylic are dominant binding sites at acidic $\mathrm{pH}$. Indeed, our study $\mathrm{pH}$ spans a 2 to 10 range with an analytical window lied in the 2-6 range, whereas in Yamamoto et al. $(2005,2006)$ experiments $\mathrm{pH}$ varies between 4 and 5.5 and, in Sonke and 
Salters (2005) it varies between 6 and 9. Eventually, the understanding of this fractionation is not obvious and such a MREE downward concavity remains to be explained.

However, the similar MREE downward concavity patterns observed for REE complexation with HA (present study), with FA (Yamamoto et al., 2005) and with model molecule of carboxylic sites (acetic acid) (Wood, 1993), evidence that this type of fractionation could be expected in natural systems. Endly, the comparison of Sonke and Salters (2006), Yamamoto et al. (2005), and present datasets allow validating the new $\log \mathrm{K}_{\mathrm{MA}}$ (REE-HA) dataset presented in this study which could be then used to predict REE speciation in natural waters.

\subsection{REE speciation in natural river and soil waters}

Location of Fig. 6.

Several authors confer a major role to the colloidal fraction in the transport of REE by rivers (Hoyle et al., 1984; Goldstein and Jacobsen, 1988; Cantrell and Byrne, 1987; Elderfield et al., 1990; Sholkovitz, 1992). Elderfield et al. (1990) proposed for example the existence of two REE compartments in river waters (Fig. 6): (i) a "truly" dissolved pool, LREE depleted, but HREE enriched (Fig. 6a) and (ii) a "colloidal" pool LREE enriched and HREE flat, i.e., close to UCC (Fig. 6b) (Taylor and McLennan, 1985). Several studies have suggested that the HREE enrichment of the dissolved pool may be due to the greater solubility of HREE carbonate complexes as compared to LREE carbonate ones (Goldstein and Jacobsen, 1988; Elderfield et al., 1990; Sholkovitz, 1992). However, one of the characteristics of some river waters is that $(\mathrm{La} / \mathrm{Sm})_{\mathrm{UCC}}$ and $(\mathrm{Gd} / \mathrm{Yb})_{\mathrm{UCC}}$ ratios are commonly lower than and higher than 1 , respectively, producing a concave REE pattern (Fig. 6b) (Goldstein and Jacobsen, 1988; Elderfield et al., 1990; Sholkovitz, 1995; Viers et al., 1997; Deberdt et al., 2002). Such a 
characteristic is also well evidenced in organic rich groundwaters (Viers et al., 1997; Dia et al., 2000; Deberdt et al., 2002; Gruau et al., 2004). As shown on Fig. 7, (Gd/Yb) $)_{U C C}$ ratios increase while DOC content increases (Goldstein and Jacobsen, 1988; Elderfield et al., 1990; Sholkovitz, 1995; Viers et al., 1997; Deberdt et al., 2002). These features are further illustrated by ultrafiltration studies of organic rich river- and ground-water samples. They indicate the absence of fractionation of HREE relative to LREE with decreasing pore-size cutoff (allowing colloidal separation) in the wide range of investigated $\mathrm{pH}$ (from 5.6 to 7.7 ) (Sholkovitz, 1995; Viers et al., 1997; Douglas et al., 1999; Dupré et al., 1999; Dia et al., 2000; Deberdt et al., 2002), they even evidence for some of them a MREE downward concavity fractionation (e.g., Fig. 15 in Sholkovitz, 1995). However, such a fractionation alone could not explain the whole REE pattern fractionation. Indeed, Johannesson et al. (1996a) suggested that MREE enrichment in hypersaline waters is the result of mineral weathering due to dissolution of MREE-enriched Fe- and Mn-rich particulates or surface coatings. Hannigan and Sholkovitz (2001) also proposed that MREE enrichment has to be related to the weathering of co-precipitated phosphates minerals. The present study demonstrates that organic substances plays a major control onto REE speciation and thus onto REE fractionation pattern. Based on this ability of HA to preferentially complex MREE, REE fractionation patterns at the Earth's surface can be revisited. DOC-rich river- and groundwaters REE patterns may reflect a mixing between (i) dissolved fraction of DOC-rich soil solutions, surface runoff and river waters which display MREE downward concavity patterns (Viers et al., 1997; Dia et al., 2000; Deberdt et al., 2002; Gruau et al., 2004); and (ii) river suspended particles which are slightly LREE enriched inherited from preferential adsorption of LREE (Sholkovitz, 1995).

Location of Fig. 7. 
Up to now investigations of REE speciation in natural river and soil waters were performed using Model V and Model VI with extrapolated constants obtained from Linear Free-Energy Relationships (LFER) (Tang and Johannesson, 2003; Pourret et al., 2007) and using Model V with constants fitted from experimental complexation between REE and HM (Sonke, 2006). Using the new determined log $\mathrm{K}_{\mathrm{MA}}$ dataset, REE speciation calculations - as a function of $\mathrm{pH}$ - were performed for the World Average River Water (Tang and Johannesson, 2003) in order to validate the results obtained with extrapolated constants. Major ions such as Fe and $\mathrm{Al}$ were adopted for re-calculating the REE speciation of the modelled World Average River Water (see Table 11 in Tang and Johannesson, 2003). We also followed their assumption that $80 \%$ of the active HM in this sample is present as FA and $20 \%$ as HA. Thus, the DOM content of World Average River Water is $10 \mathrm{mg} \mathrm{L}^{-1}$, of which only $5 \mathrm{mg} \mathrm{L}^{-1}$ consist of $\mathrm{HM}$ able to complex with the REE, with $4 \mathrm{mg} \mathrm{L}^{-1}(80 \%)$ present as FA, and $1 \mathrm{mg} \mathrm{L}^{-1}$ (20 $\%)$ as HA. Since $\mathrm{pH}$ is a key parameter to REE speciation, the REE speciation calculations were performed in the same way of these authors (op. cit.), i.e., holding the major solute composition constant (except carbonate alkalinity varying as a function of $\mathrm{pH}$ ). Moreover, a fair degree of similarity between the model constants obtained for fulvic and humic acids exists as previously stated (Tipping and Hurley, 1992; Tipping, 1998) so log $\mathrm{K}_{\mathrm{MA}}(\mathrm{FA})$ were calculated from log $\mathrm{K}_{\mathrm{MA}}(\mathrm{HA})$, obtained in section 3, using Eq. 19 in Tipping (1998). Binding of $\mathrm{REE}(\mathrm{OH})$ species and $\mathrm{Fe}$ and $\mathrm{Al}$ oxyhydroxide precipitation were not considered in our calculation

Location of Fig. 8.

The obtained results are shown for $\mathrm{La}, \mathrm{Eu}$, and Lu in Fig. 8. The REE-HM species represent the proportion of each REE complexed with humic substances. The Model VI results are consistent with earlier investigations performed using Model V and Model VI with extrapolated constants from LFER (Tang and Johannesson, 2003; Sonke, 2006; Pourret et al., 
2007). Model VI predicts that (i) REE occur predominantly as organic complexes (REE-HM $\geq 60 \%$ ) in the $\mathrm{pH}$ range between 5-5.5 and 7-8.5 (i.e., circumneutral $\mathrm{pH}$ waters), (ii) REEHM complexes become progressively less important with increasing atomic number across the REE series, and (iii) $\mathrm{pH}$ at which proportion of REE-HM species is maximum decreases from La to Lu. The only noticeable difference is that the new fitted constants allow Model VI to calculate significantly higher proportions of REE complexed with organic matter at high $\mathrm{pH}$ conditions than with extrapolated constants as already proposed by Sonke (2006) using Model V. As an example, with the fitted constants Model VI predicts La-HM $85 \%$ at $\mathrm{pH} 9$, while with extrapolated constants it only predicts $60 \%$ of La-HM. However, these new calculations are also a validation of the LFER method (Tang and Johannesson, 2003; Pourret et al., 2007). Moreover, these results are coherent with simple speciation calculations performed by Takahashi and co-workers (Takahashi et al., 1997; Takahashi et al., 1999) which led them to speculate that humate complexes should be the dominant species of REE(III) dissolved in natural aquifers where DOM occurs significantly.

\section{Conclusions}

Experimental studies of REE-HA binding were carried out using an ultrafiltration method. A strong $\mathrm{pH}$ dependence resulting in a significant increase in the proportion of REEHA with increasing $\mathrm{pH}$ and a MREE downward concavity fractionation at acidic $\mathrm{pH}$ were observed. Moreover, modelling was performed using Humic Ion Binding Model VI. Experimental results were fitted to obtain a set of constants $\left(\log \mathrm{K}_{\mathrm{MA}}\right)$. The constants presented in our study are in good agreement with some literature constants. However, they are different from those published by Takahashi et al. (1997) and Sonke and Salters (2006) which evidences a lanthanide contraction effect. Model VI constants in this study indicate that 
REE-HA complexation involved a fractionation similar to the REE complexation with simple carboxylic groups such as acetates. The similar MREE downward concavity pattern observed for REE complexation with HA (this study), with FA (Yamamoto et al., 2005) and with simple organic acid such as acetic acid (Wood, 1993; Byrne and Li, 1995), illustrates that this type of fractionation could be expected in natural systems. All these observations allow validating the present $\log \mathrm{K}_{\mathrm{MA}}$ (REE-HA) dataset that can be, therefore, used with confidence to predict REE speciation in natural waters. Essentially, experiments from this study coupled to observation made by Takahashi et al. (1997), Yamamoto et al. (2005; 2006) and Sonke and Salters (2006) allow covering a wide range of experimental conditions both in HS/Ln ratio and in $\mathrm{pH}$ range (from 2 to 10) and are thus complementary. Moreover, the results of the present study shed more light on the REE cycle at the Earth's surface. They confirm that organic REE speciation plays a major role onto REE fractionation in natural organic-rich river- and groundwaters. Dissolved fractions of DOC-rich soil solutions, surface runoff, and river waters display MREE downward concavity patterns. The new $\log \mathrm{K}_{\mathrm{MA}}$ were additionally introduced in WHAM 6 to predict speciation of the World Average River Water. REE occur predominantly as organic complexes (REE-HM $\geq 60$ $\%)$ in circumneutral $\mathrm{pH}$ waters $(\mathrm{pH}$ range between 5-5.5 and 7.5-8). New fitted constants allow Model VI to calculate high proportions of LREE complexed with organic matter under alkaline $\mathrm{pH}$ conditions. Overall, the results of this study suggest that further considerations about organic matter should be taken into account to model and thus better understand global continent-ocean trace metal cycles. 
Acknowledgements. We thank the technical staff at Rennes (M. Le Coz-Bouhnik, O. Hénin and P. Petitjean) for their assistance during the experimental and analytical work. Dr. R. E. Martinez is acknowledged for useful discussions and English corrections. Dr. J.E. Sonke and an anonymous reviewer are thanked for thorough and constructive comments of an earlier version of this paper. This research was supported by the CPER programs "Développement de la Recherche sur la Maîtrise de la Qualité de l'Eau en Bretagne" jointly funded by the French Government and the Council of Rennes Métropole. 


\section{References}

Avena, M.J., Vermeer, A.W.P. and Koopal, L.K., 1999. Volume and structure of humic acids studied by viscometry $\mathrm{pH}$ and electrolyte concentration effects. Colloids and Surfaces A, 151: 213-224.

Bidoglio, G., Grenthe, I., Qi, P., Robouch, P. and Omenetto, N., 1991. Complexation of Eu and $\mathrm{Tb}$ with fulvic acids as studied by time-resolved laser induced fluorescence. Talanta, 38: 999-1008.

Byrne, R.H. and Kim, K.-H., 1990. Rare earth element scavenging in seawater. Geochimica et Cosmochimica Acta, 54: 2645-2656.

Byrne, R.H. and Li, B., 1995. Comparative complexation behavior of the rare earths. Geochimica et Cosmochimica Acta, 59: 4575-4589.

Cantrell, K.J. and Byrne, R.H., 1987. Rare earth element complexation by carbonate and oxalate ions. Geochimica et Cosmochimica Acta, 51: 597-605.

Crawford, M.B., 1996. PHREEQEV: the incorporation of a version of Model V for organic complexation in aqueous solutions into the speciation code PHREEQE. Computers \& Geosciences, 22: 109-116.

Davranche, M., Pourret, O., Gruau, G. and Dia, A., 2004. Impact of humate complexation on the adsorption of REE onto Fe oxyhydroxide. Journal of Colloid and Interface Science, 277: 271-279.

Davranche, M., Pourret, O., Gruau, G., Dia, A. and Le Coz-Bouhnik, M., 2005. Adsorption of $\mathrm{REE}(\mathrm{III})$-humate complexes onto $\mathrm{MnO}_{2}$ : Experimental evidence for cerium anomaly and lanthanide tetrad effect suppression. Geochimica et Cosmochimica Acta, 69: $4825-4835$. 
De Baar, H.J.W., Schijf, J. and Byrne, R.H., 1991. Solution chemistry of the rare earth elements in seawater. European Journal of Solid State and Inorganic Chemistry, 28: $357-373$.

Deberdt, S., Viers, J. and Dupré, B., 2002. New insights about the rare earth elements (REE) mobility in river waters. Bulletin de la Société Géologique de France, 173: 147-160.

Dia, A. et al., 2000. The distribution of rare earth elements in groundwaters: assessing the role of source-rock composition, redox changes and colloidal particle. Geochimica et Cosmochimica Acta, 64: 4131-4151.

Dierckx, A., Maes, A. and Vancluysen, J., 1994. Mixed complex formation of $\mathrm{Eu}^{3+}$ with humic acid and a competing ligand. Radiochimica Acta, 66/67: 149-156.

Douglas, G.B., Hart, B.T., Beckett, R., Gray, C.M. and Oliver, R.L., 1999. Geochemistry of suspended particulate matter (SPM) in the Murray-Darling River system: a conceptual isotopic/geochemical model for the fractionation of major, trace and rare earth elements. Aquatic Geochemistry, 5: 167-194.

Dupré, B. et al., 1999. Major and trace elements associated with colloids in organic-rich river waters: ultrafiltration of natural and spiked solutions. Chemical Geology, 160: 63-80.

Elderfield, H. and Greaves, M.J., 1982. The rare earth elements in seawater. Nature, 296: 214219.

Elderfield, H., Upstill-Goddard, R. and Sholkovitz, E.R., 1990. The rare earth elements in rivers, estuaries, and coastal seas and their significance to the composition of ocean waters. Geochimica et Cosmochimica Acta, 54: 971-991.

Fairhurst, A.J., Warwick, P. and Richardson, S., 1995. The influence of humic acid on the adsorption of europium onto inorganic colloids as a function of $\mathrm{pH}$. Colloids and Surfaces A, 99: 187-199. 
Franz, C., Herrmann, G. and Trautmann, N., 1997. Complexation of Samarium(III) and Americium(III) with humic acid at very low metal concentrations. Radiochimica Acta, 77: $177-181$.

Goldstein, S.J. and Jacobsen, S.B., 1988. Rare earth elements in river waters. Earth and Planetary Sciences Letters, 89: 35-47.

Gruau, G., Dia, A., Olivié-Lauquet, G., Davranche, M. and Pinay, G., 2004. Controls on the distribution of rare earth elements in shallow groundwaters. Water Research, 38: 3576-3586.

Hannigan, R.E. and Sholkovitz, E., 2001. The development of middle rare earth element enrichments in freshwaters: weathering of phosphate minerals. Chemical Geology, 175: 495-508.

Henderson, P., 1984. Rare earth element geochemistry. Elsevier, Amsterdam.

Hoyle, J., Elderfield, H., Gledhill, A. and Greaves, M., 1984. The behaviour of rare earth elements during mixing of river and sea waters. Geochimica et Cosmochimica Acta, 48: 143-149.

Hummel, W., Glaus, M. and Van Loon, L.R., 1995. Binding of radionuclides by humic substances: the "conservative roof" approach, Proceeding of an NEA Workshop, 1416 september 1994. OECD Documents, Bas Zurzach, Switzerland, pp. 251-262.

Ingri, J. et al., 2000. Temporal variations in the fractionation of the rare earth elements in a boreal river; the role of colloidal particles. Chemical Geology, 166: 23-45.

Johannesson, K.H., Lyons, W.B., Yelken, M.A., Gaudette, H.E. and Stetzenbach, K.J., 1996a. Geochemistry of the rare earth elements in hypersaline and dilute acidic natural terrestrial waters: complexation behavior and middle rare-earth element enrichments. Chemical Geology, 133: 125-144. 
Johannesson, K.H., Stetzenbach, K.J. and Hodge, V.F., 1997. Rare earth elements as geochemical tracers of regional groundwater mixing. Geochimica et Cosmochimica Acta, 61: 3605-3618.

Johannesson, K.H., Stetzenbach, K.J., Hodge, V.F. and Lyons, W.B., 1996b. Rare earth element complexation behavior in circumneutral $\mathrm{pH}$ groundwaters: Assessing the role of carbonate and phosphate ions. Earth and Planetary Sciences Letters, 139: 305-319.

Johannesson, K.H., Tang, J., Daniels, J.M., Bounds, W.J. and Burdige, D.J., 2004. Rare earth element concentrations and speciation in organic-rich blackwaters of the Great Dismal Swamp, Virginia, USA. Chemical Geology, 209: 271-294.

Johannesson, K.H., Zhou, X., Guo, C., Stetzenbach, K.J. and Hodge, V.F., 2000. Origin of rare earth element signatures in groundwaters of circumneutral $\mathrm{pH}$ from southern Nevada and eastern California, USA. Chemical Geology, 164: 239-257.

Kubota, T., Tochiyama, O., Tanaka, K. and Niibori, Y., 2002. Complex formation of Eu(III) with humic acid and polyacrylic acid. Radiochimica Acta, 90: 569-574.

Lead, J.R., Hamilton-Taylor, J., Peters, A., Reiner, S. and Tipping, E., 1998. Europium binding by fulvic acids. Analytica Chimica Acta, 369: 171-180.

Lee, J.H. and Byrne, R.H., 1992. Examination of comparative rare earth element complexation behavior using linear free-energy relationships. Geochimica et Cosmochimica Acta, 56: 1127-1137.

Lee, J.H. and Byrne, R.H., 1993. Complexation of trivalent rare earth elements (Ce, Eu, Gd, $\mathrm{Tb}, \mathrm{Yb}$ ) by carbonate ions. Geochimica et Cosmochimica Acta, 57: 295-302.

Lippold, H., Müller, N. and Kupsch, H., 2005. Effect of humic acid on the pH-dependent adsorption of terbium(III) onto geological materials. Applied Geochemistry, 20: 12091217. 
Liu, X. and Byrne, R.H., 1998. Comprehensive investigation of yttrium and rare earth element complexation by carbonate using ICP-Mass Spectrometry. Journal of Solution Chemistry, 9: 803-815.

Luo, Y.-R. and Byrne, R.H., 2004. Carbonate complexation of Yttrium and the rare earth elements in natural rivers. Geochimica et Cosmochimica Acta, 68: 691-699.

Maes, A., De Brabandere, J. and Cremers, A., 1988. A modified Schubert method for the measurement of the stability of europium humic acid complexes in alkaline conditions. Radiochimica Acta, 44/45: 51-57.

Milne, C.J., Kinniburgh, D.G. and Tipping, E., 2001. Generic NICA-Donnan Model parameters for proton binding by humic substances. Environmental Science \& Technology, 35: 2049-2059.

Milne, C.J., Kinniburgh, D.G., Van Riemsdijk, W.H. and Tipping, E., 2003. Generic NICADonnan Model parameters for metal-ion binding by humic substances. Environmental Science \& Technology, 37: 958-971.

Millero, F.J., 1992. Stability constants for the formation of rare earth inorganic complexes as a function of ionic strength. Geochimica et Cosmochimica Acta, 56: 3123-3132.

Moulin, V. et al., 1992. Complexation behaviour of humic substances towards actinides and lanthanides studied by Time-Resolved Laser-Induced Spectrofluometry. Radiochimica Acta, 58/59: 121-128.

Nordén, M., Ephhraim J.H. and Allard, B., 1993. The binding of strontium and europium by an aquatic fulvic acid-ion exchange distribution and ultrafiltration studies. Talanta, 40: $1425-1432$.

Pourret, O., Davranche, M., Gruau, G. and Dia, A., 2007. Organic complexation of rare earth elements in natural waters: Evaluating model calculations from ultrafiltration data. Geochimica et Cosmochimica Acta, doi: 1016/j.gca.2007.04.001. 
Saito, T., Nagasaki, S., Tanaka, S. and Koopal, L.K., 2005. Electrostatic interactions models for ion binding to humic substances. Colloids and Surfaces A, 265: 104-113.

Sholkovitz, E.R., 1992. Chemical evolution of rare earth elements: fractionation between colloidal and solution phases of filtered river water. Earth and Planetary Sciences Letters, 114: 77-84.

Sholkovitz, E.R., 1995. The aquatic chemistry of rare earth elements in rivers and estuaries. Aquatic Geochemistry, 1: 1-34.

Smedley, P.L., 1991. The geochemistry of rare earth elements in groundwater from the Carnmenellis area, southwest England. Geochimica et Cosmochimica Acta, 55: 27672779.

Sonke, J.E., 2006. Lanthanide-humic substances complexation. II. Calibration of Humic IonBinding Model V. Environmental Science \& Technology, 40: 7481-7487.

Sonke, J.E. and Salters, V.J.M., 2006. Lanthanide-humic substances complexation. I. Experimental evidence for a lanthanide contraction effect. Geochimica et Cosmochimica Acta, 70: 1495-1506.

Takahashi, Y., Minai, Y., Ambe, S., Makide, Y. and Ambe, F., 1999. Comparison of adsorption behavior of multiple inorganic ions on kaolinite and silica in the presence of humic acid using the multitracer technique. Geochimica et Cosmochimica Acta, 63: 815-836.

Takahashi, Y. et al., 1997. Simultaneous determination of stability constants of humate complexes with various metal ions using multitracer technique. The Science of the Total Environment, 198: 61-71.

Tang, J. and Johannesson, K.H., 2003. Speciation of rare earth elements in natural terrestrial waters: Assessing the role of dissolved organic matter from the modeling approach. Geochimica et Cosmochimica Acta, 67: 2321-2339. 
Taylor, S.R. and McLennan, S.M., 1985. The Continental Crust: Its composition and evolution. Blackwell, Oxford, pp. 312.

Thurman, E.M., 1985. Organic Geochemistry of Natural Waters, Dordrechtthe, Netherlands.

Tipping, E., 1998. Humic Ion-Binding Model VI: an improved description of the interactions of protons and metal ions with humic substances. Aquatic Geochemistry, 4: 3-48.

Tipping, E. and Hurley, M.A., 1992. A unifying model of cation binding by humic substances. Geochimica et Cosmochimica Acta, 56: 3627-3641.

Vermeer, A.W.P., Van Riemsdijk, W.H. and Koopal, L.K., 1998. Adsorption of humic acid to mineral particles. 1. Specific and Electrostatic Interactions. Langmuir, 14: 2810-2819.

Viers, J. et al., 1997. Chemical weathering in the drainage basin of a tropical watershed (Nsimi-Zoetele site, Cameroon): comparison between organic-poor and organic-rich waters. Chemical Geology, 140: 181-206.

Wood, S.A., 1990. The aqueous geochemistry of the rare-earth elements and yttrium. 1. Review of the available low-temperature data for inorganic complexes and inorganic REE speciation in natural waters. Chemical Geology, 82: 159-186.

Wood, S.A., 1993. The aqueous geochemistry of the rare-earth elements: Critical stability constants for complexes with simple carboxylic acids at $25^{\circ} \mathrm{C}$ and 1 bar and their application to nuclear waste management. Engineering Geology, 34: 229-259.

Yamamoto, Y., Takahashi, Y. and Shimizu, H., 2005. Systematics of stability constants of fulvate complexes with rare earth ions. Chemistry Letters, 34: 880-881.

Yamamoto, Y., Takahashi, Y. and Shimizu, H., 2006. Interpretation of REE patterns in natural water based on the stability constants. Geochimica et Cosmochimica Acta, Goldschmidt Conference Abstracts: doi:10.1016/j.gca.2006.06.1587. 


\section{Figure, Table and Appendix Captions}

Fig. 1. Proportions of (a) La-HA, (b) Eu-HA and (c) Lu-HA complexes as a function of pH for various HA concentrations.

Fig. 2. Proportions of REE bound to HA as a function of $\mathrm{pH}$ for various HA concentrations (a) $5 \mathrm{mg} \mathrm{L}^{-1}$, (b) $10 \mathrm{mg} \mathrm{L}^{-1}$ and (c) $20 \mathrm{mg} \mathrm{L}^{-1}$.

Fig. 3. Binding of La by HA. Dependence on $\mathrm{pH}$ of $\%$ La bound, measured by ultrafiltration; the solid line is the best fit and the dash line represents the calculated binding for the overall average $\log \mathrm{K}_{\mathrm{MA}}$ (2.58) for various HA concentrations (a) $5 \mathrm{mg} \mathrm{L}^{-1}$, (b) $10 \mathrm{mg} \mathrm{L}^{-1}$, (c) $20 \mathrm{mg}$ $\mathrm{L}^{-1}$

Fig. 4. REE patterns for (a) $\log \beta$ (REE-acetic acid), $\log \beta$ (REE-humic acid) ${ }^{\mathrm{a}}, \log \beta$ (REEfulvic acid) ${ }^{\mathrm{a}}$ and $\log \mathrm{K}_{\mathrm{MA}}\left(\right.$ REE-humic acid) ${ }^{\mathrm{b}}$ and (b) $\log \beta$ (REE-EDTA), $\log \beta$ (REE-fulvic acid $^{\mathrm{c}}$ and $\log \beta(\text { REE-humic acid })^{\mathrm{c}}$.

${ }^{\mathrm{a}}$ Yamamoto et al. (2006); ${ }^{\mathrm{b}}$ this study; ${ }^{\mathrm{c}}$ Sonke and Salters (2006).

Fig. 5. Literature compilation of REE-organic ligand constants (recalculated at $I=0.1 \mathrm{M}$ when necessary; Wood, 1993; Byrne and Li, 1995). black triangles: amino-carboxylic acids; white squares: iminoacetic acids; black circles: phenolic acids; grey circles: carboxylic acids; white circles: natural carboxylic acids: dark grey circles: humic substances, Aldrich Humic Acid (AHA), Suwannee River Fulvic Acid (SRFA), Suwannee River Humic Acid (SRHA) and Leonardite Humic Acid (LHA) ( ${ }^{\mathrm{a}}$ this study; ${ }^{\mathrm{b}}$ Yamamoto et al. (2006); ${ }^{\mathrm{c}}$ Sonke and Salters (2006)). 
Fig. 6. REE normalized (to UCC) (Taylor and McLennan, 1985) patterns of river waters showing (a) HREE enrichment and (b) MREE enrichment (Goldstein and Jacobsen, 1988; Elderfield et al., 1990; Sholkovitz, 1995; Deberdt et al., 2002), and (c) soil waters showing MREE enrichment (Viers et al., 1997; Dia et al., 2000; Gruau et al., 2004).

Fig. 7. $(\mathrm{Gd} / \mathrm{Yb})_{\mathrm{UCC}}$ ratios as a function of DOC concentrations; data are from river waters presented in Fig. 6 (when no DOC concentrations available a concentration of 1 was assumed for comparison purpose (Thurman, 1985)).

Fig. 8. Model VI speciation calculations for (a) La, (b) Eu and (c) Lu in World Average River Water as a function of $\mathrm{pH}$.

Table 1. Model VI parameters for humic acid (Tipping, 1998).

Table 2. Log $\mathrm{K}_{\mathrm{MA}}$ values obtained for the three datasets using Model VI. rmse refers to root mean square error of the regression analysis (see text for details) while sd refers to standard deviation on the mean.

Table 3. Experimental conditions and fit of literature data (IE: ion exchange; S: spectrofluorometry). rmse corresponds to root mean square error of the regression analysis (see text for detail). 
Table 4. Log $\mathrm{K}_{\mathrm{MA}}$ values obtained for the four Sonke and Salters' datasets (2006) using Model VI (pH 6 to 9, $0.1 \mathrm{~mol} \mathrm{~L}^{-1} \mathrm{NaNO}_{3}, 100 \mathrm{nmol} \mathrm{L}{ }^{-1} \mathrm{REE}, 10 \mathrm{mg} \mathrm{L}^{-1} \mathrm{LHA}$ and $500 \mathrm{nmol} \mathrm{L}^{-1}$ EDTA).

Appendix A. Proportion of REE-HA. 

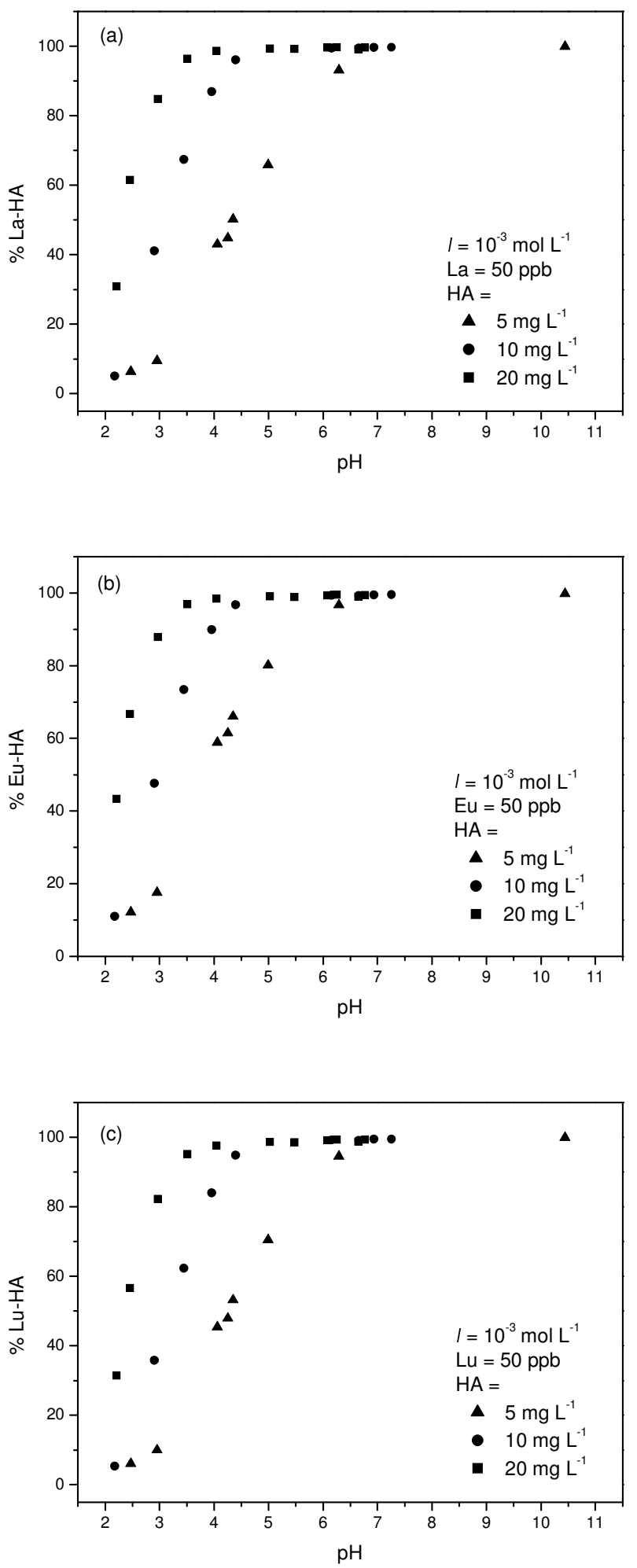

Fig. 1. 

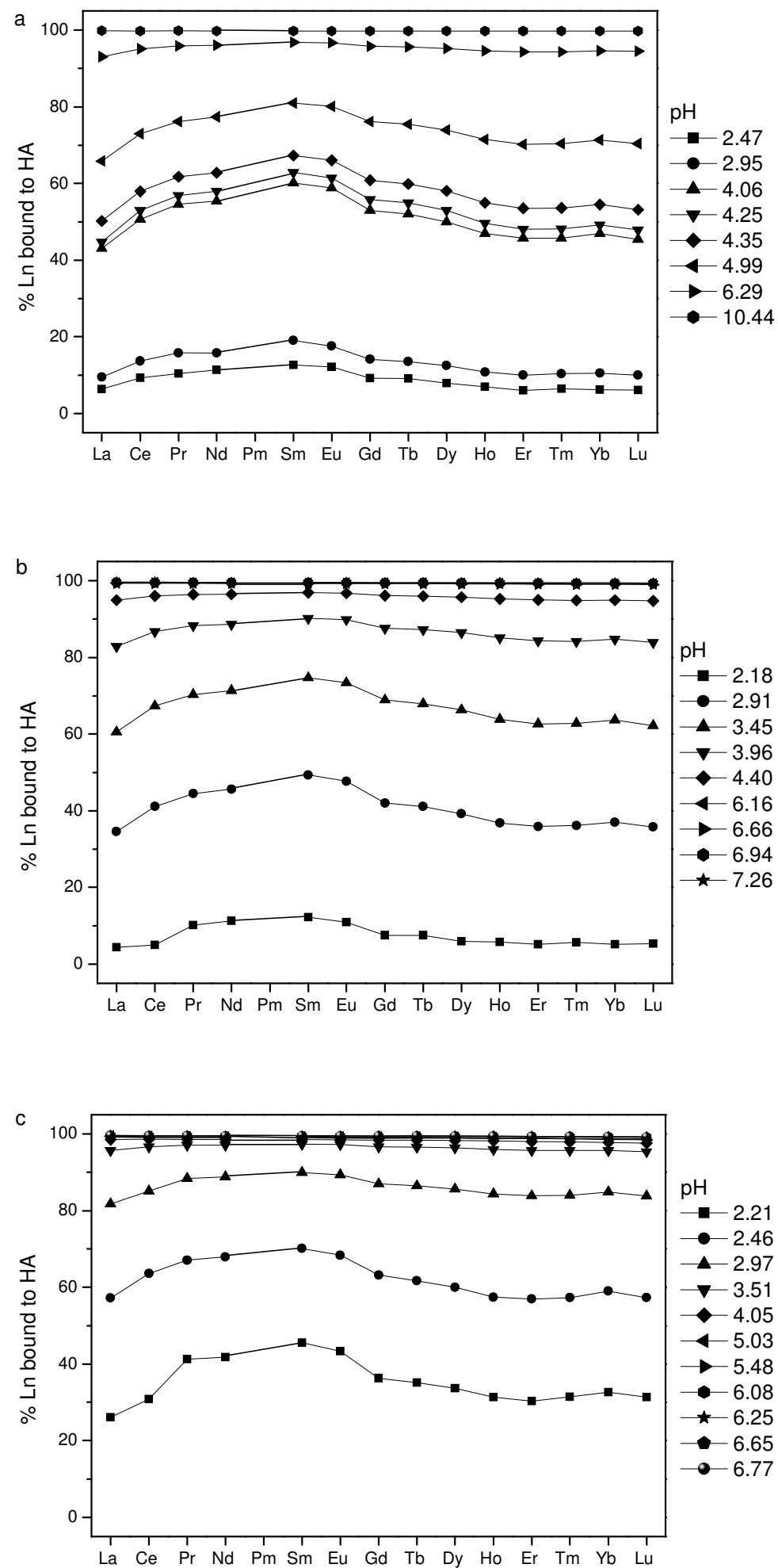

Fig. 2 

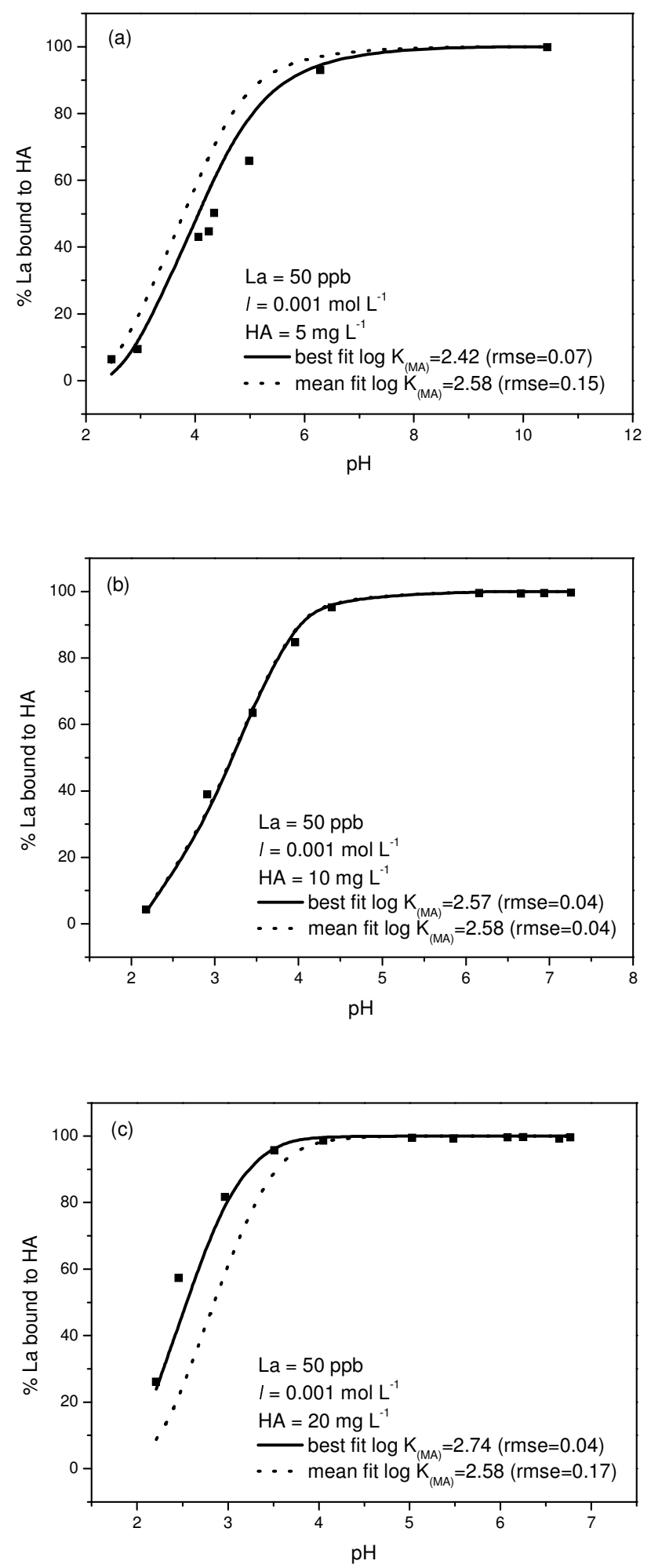

Fig. 3. 

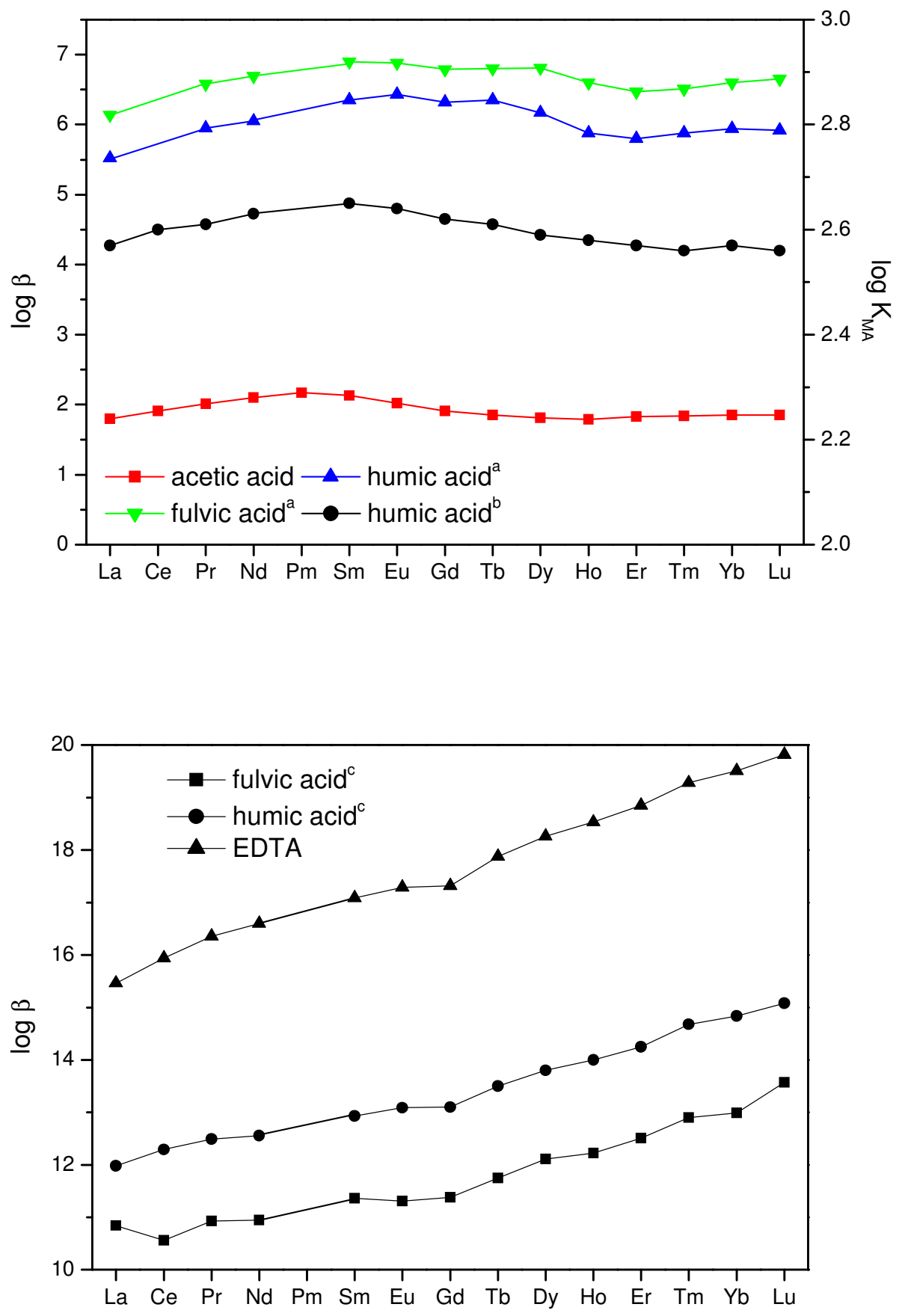

Fig. 4. 


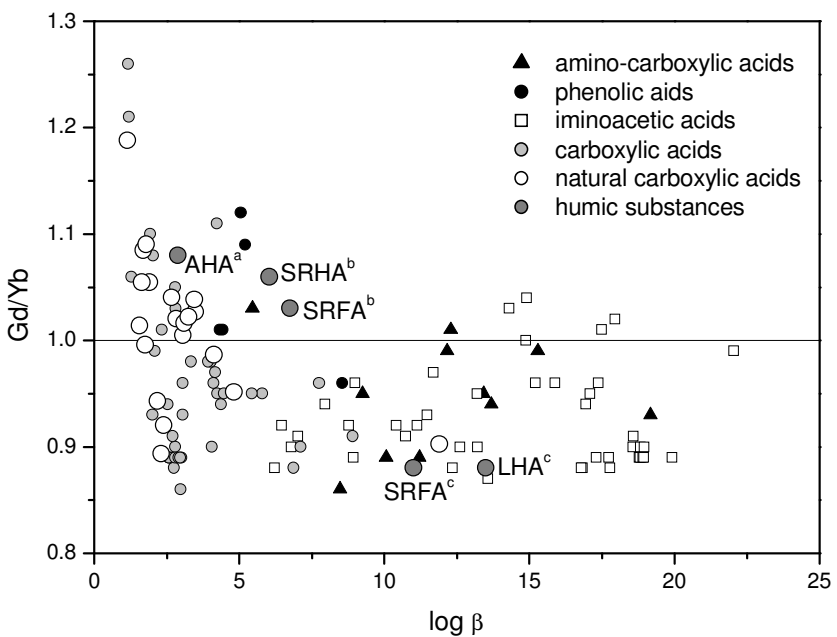

Fig. 5. 

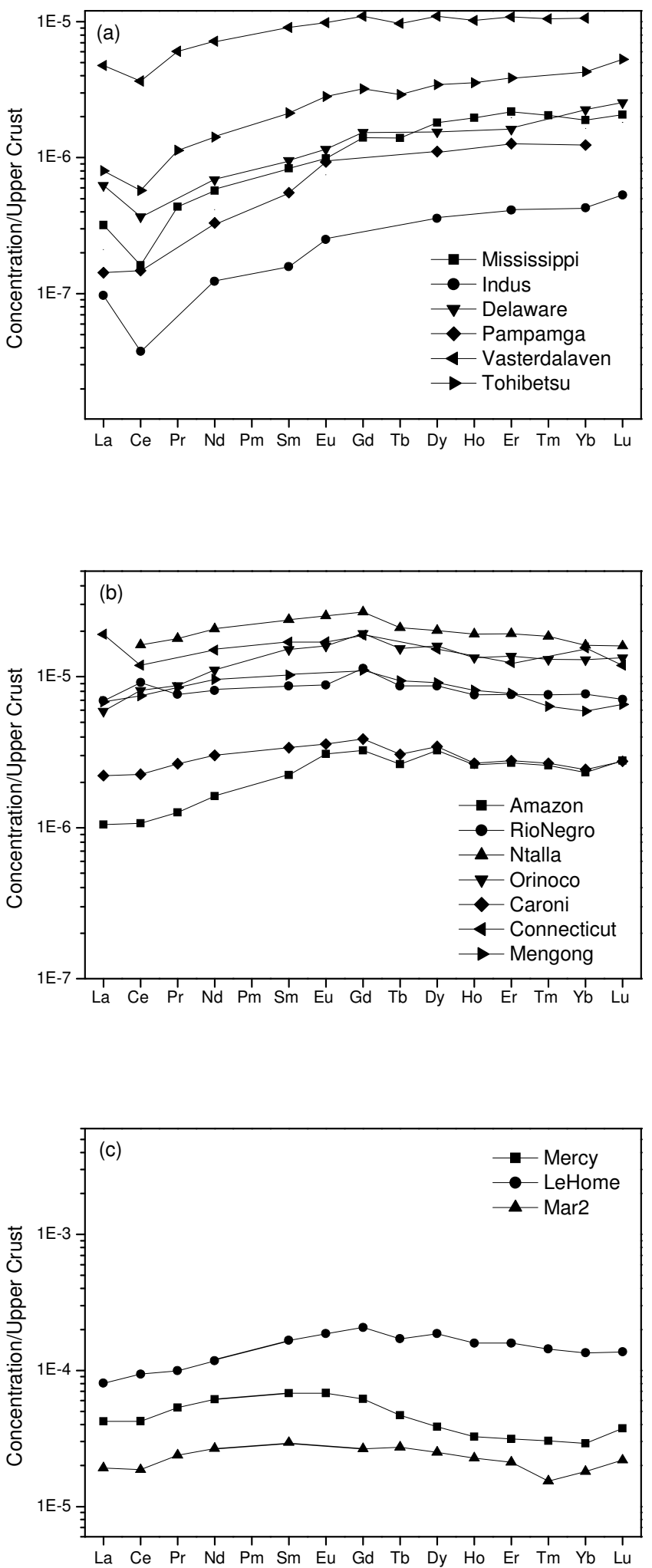

Fig. 6. 


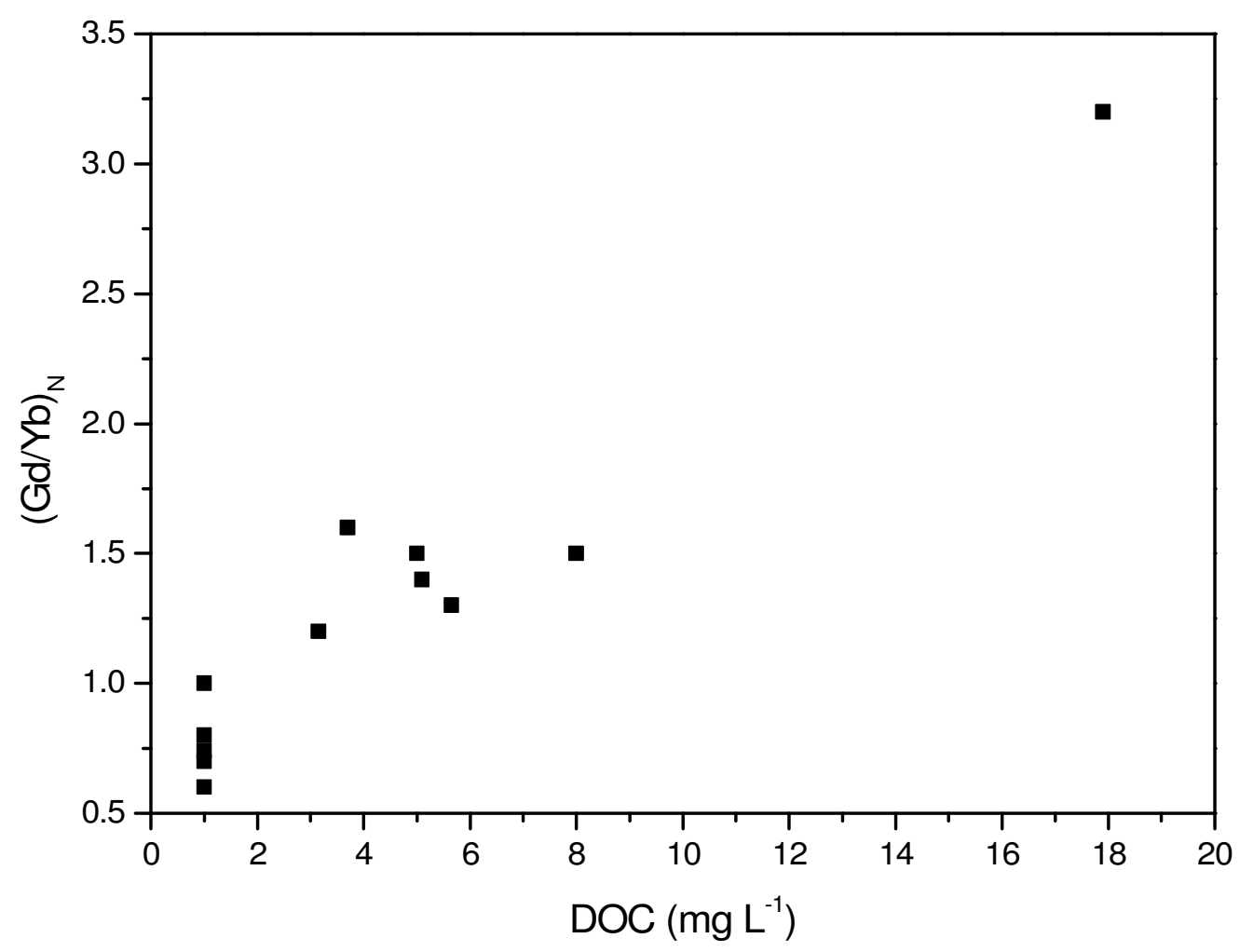

Fig. 7. 

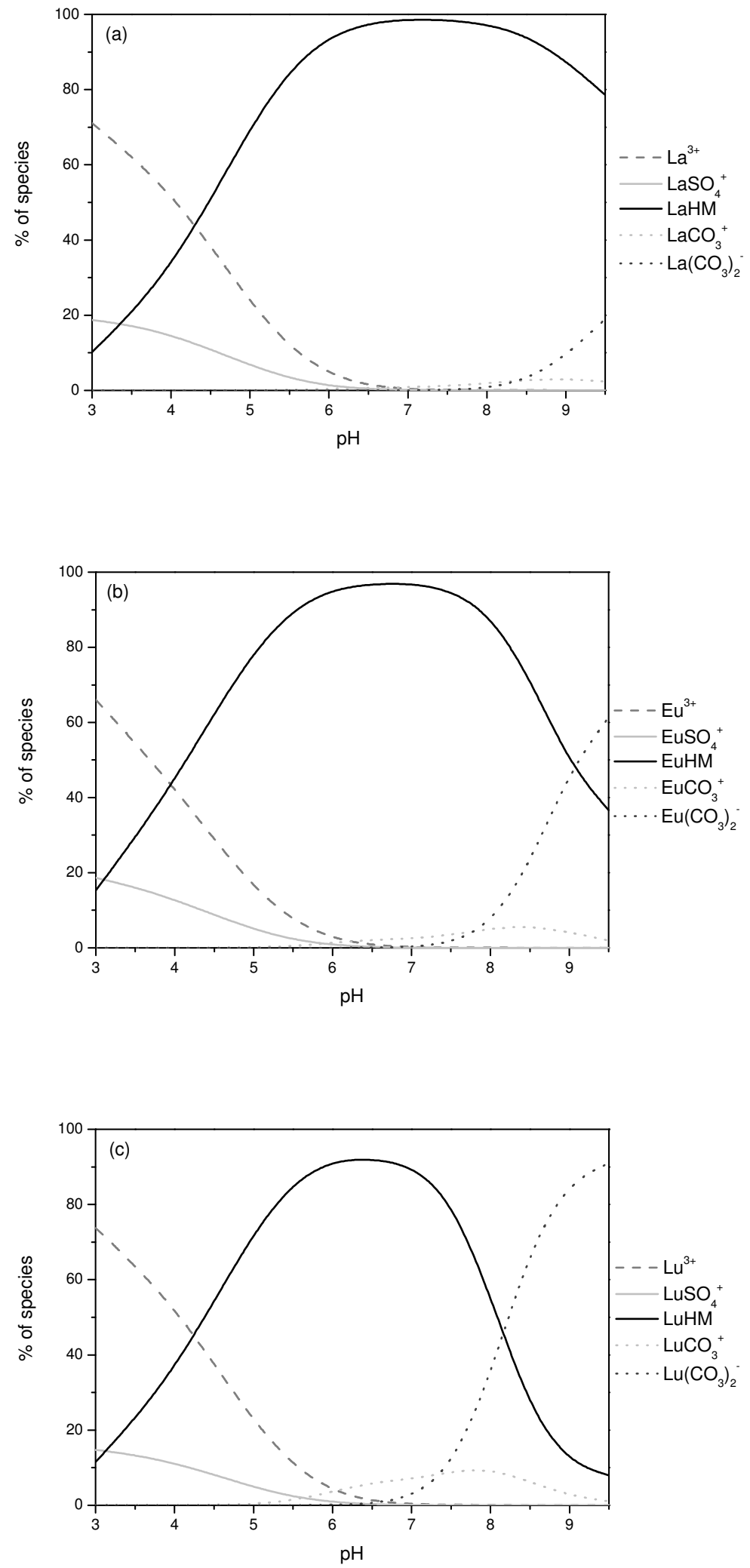

Fig. 8. 


\begin{tabular}{lll}
\hline Parameter & Description & Values \\
\hline $\mathrm{n}_{\mathrm{A}}$ & Amount of type A sites $\left(\mathrm{mol} \mathrm{g}^{-1}\right)$ & $3.310^{-3}$ \\
$\mathrm{n}_{\mathrm{B}}$ & Amount of type B sites $\left(\mathrm{mol} \mathrm{g}^{-1}\right)$ & $0.5 \times \mathrm{n}_{\mathrm{A}}$ \\
$\mathrm{pK}_{\mathrm{A}}$ & Intrinsic proton dissociation constant for type A sites & 4.1 \\
$\mathrm{pK}_{\mathrm{B}}$ & Intrinsic proton dissociation constant for type B sites & 8.8 \\
$\Delta \mathrm{pK}_{\mathrm{A}}$ & Distribution terms that modifies $\mathrm{pK}_{\mathrm{A}}$ & 2.1 \\
$\Delta \mathrm{pK}_{\mathrm{B}}$ & Distribution terms that modifies $\mathrm{pK}_{\mathrm{B}}$ & 3.6 \\
$\log \mathrm{K}_{\mathrm{MA}}$ & Intrinsic equilibrium constant for metal binding at type A sites & Fitted from experimental data \\
$\log \mathrm{K}_{\mathrm{MB}}$ & Intrinsic equilibrium constant for metal binding at type B sites & $3.39 \log \mathrm{K}_{\mathrm{MA}}-1.15$ \\
$\Delta \mathrm{LK}_{1}$ & Distribution term that modifies log K & $2.8(\mathrm{REE})$ \\
$\Delta \mathrm{LK}_{2}$ & Distribution term that modifies the strengths of bidentate and tridentate sites & $0.55 \log \mathrm{K}_{\mathrm{NH} 3}=0.29(\mathrm{REE})$ \\
$\mathrm{P}$ & Electrostatic parameter & -330 \\
$\mathrm{~K}_{\mathrm{sel}}$ & Selectivity coefficient for counterion accumulation & 1 \\
$\mathrm{M}$ & Molecular weight & $15000 \mathrm{Da}$ \\
$\mathrm{r}$ & Molecular radius & $1.72 \mathrm{~nm}$ \\
\hline
\end{tabular}

Table 1 


\begin{tabular}{ccccccccc}
\hline$[\mathrm{HA}]\left(\mathrm{mg} \mathrm{L}^{-1}\right)$ & 5 & $(\mathrm{rmse})$ & 10 & $(\mathrm{rmse})$ & 20 & $(\mathrm{rmse})$ & mean & sd \\
\hline $\mathrm{La}$ & 2.42 & 0.07 & 2.57 & 0.04 & 2.74 & 0.04 & 2.58 & 0.16 \\
$\mathrm{Ce}$ & 2.44 & 0.05 & 2.60 & 0.04 & 2.77 & 0.03 & 2.60 & 0.17 \\
$\mathrm{Pr}$ & 2.45 & 0.05 & 2.61 & 0.03 & 2.78 & 0.01 & 2.61 & 0.17 \\
$\mathrm{Nd}$ & 2.47 & 0.06 & 2.63 & 0.02 & 2.79 & 0.02 & 2.63 & 0.16 \\
$\mathrm{Sm}$ & 2.50 & 0.05 & 2.65 & 0.03 & 2.81 & 0.01 & 2.65 & 0.16 \\
$\mathrm{Eu}$ & 2.50 & 0.05 & 2.64 & 0.04 & 2.80 & 0.02 & 2.65 & 0.15 \\
$\mathrm{Gd}$ & 2.48 & 0.07 & 2.62 & 0.05 & 2.79 & 0.02 & 2.63 & 0.16 \\
$\mathrm{~Tb}$ & 2.47 & 0.07 & 2.61 & 0.04 & 2.78 & 0.02 & 2.62 & 0.16 \\
$\mathrm{Dy}$ & 2.46 & 0.06 & 2.59 & 0.04 & 2.78 & 0.02 & 2.61 & 0.16 \\
$\mathrm{Ho}$ & 2.45 & 0.07 & 2.58 & 0.05 & 2.77 & 0.02 & 2.60 & 0.16 \\
$\mathrm{Er}$ & 2.45 & 0.07 & 2.57 & 0.02 & 2.77 & 0.02 & 2.60 & 0.16 \\
$\mathrm{Tm}$ & 2.44 & 0.07 & 2.56 & 0.02 & 2.76 & 0.02 & 2.59 & 0.16 \\
$\mathrm{Yb}$ & 2.45 & 0.06 & 2.57 & 0.01 & 2.77 & 0.03 & 2.60 & 0.16 \\
$\mathrm{Lu}$ & 2.44 & 0.07 & 2.56 & 0.04 & 2.76 & 0.02 & 2.59 & 0.16 \\
$\mathrm{La} / \mathrm{Sm}$ & 0.97 & & 0.97 & & 0.98 & & 0.97 & \\
$\mathrm{Gd} / \mathrm{Yb}$ & 1.01 & & 1.02 & & 1.01 & & 1.01 & \\
\hline
\end{tabular}

Table 2 


\begin{tabular}{|c|c|c|c|c|c|c|c|c|c|}
\hline $\begin{array}{c}\mathrm{RE} \\
\mathrm{E}\end{array}$ & $\begin{array}{c}{[\mathrm{REE}]\left(\begin{array}{c}\mu \mathrm{mol} \mathrm{L} \\
\left.{ }^{-}\right)\end{array}\right.} \\
\end{array}$ & $\begin{array}{c}I(\mathrm{~mol} \mathrm{~L} \\
\left.{ }^{1}\right)\end{array}$ & {$[\mathrm{HA}] \mathrm{mg} \mathrm{L}_{1}^{-}$} & $\mathrm{pH}$ & $\begin{array}{c}\text { techniqu } \\
\mathrm{e}\end{array}$ & $\begin{array}{l}\log \\
\mathrm{K}_{\mathrm{MA}} \\
\end{array}$ & $\begin{array}{c}\mathrm{rms} \\
\mathrm{e}\end{array}$ & $\mathrm{n}$ & References \\
\hline $\mathrm{Eu}$ & 0.001 & 0.05 & 10 & $\begin{array}{c}2 \text { to } \\
10\end{array}$ & IE & 2.73 & 0.01 & 7 & $\begin{array}{c}\text { Fairhurst et al., } \\
1995\end{array}$ \\
\hline $\mathrm{Eu}$ & 0.001 & 0.05 & 2 & $\begin{array}{c}2 \text { to } \\
10\end{array}$ & IE & 2.77 & 0.04 & 7 & $\begin{array}{c}\text { Fairhurst et al., } \\
1995\end{array}$ \\
\hline $\mathrm{Tb}$ & 0.100 & 0.10 & 5 & 2 to 7 & IE & 2.57 & 0.06 & 7 & Lippold et al., 2005 \\
\hline Dy & 2.000 & 0.10 & 0.5 to 9 & 5 & $S$ & 3.19 & 0.03 & $\begin{array}{l}1 \\
3\end{array}$ & Moulin et al., 1992 \\
\hline
\end{tabular}

Table 3 


\begin{tabular}{ccccc}
\hline $\mathrm{pH}$ & 6 & 7 & 8 & 9 \\
\hline $\mathrm{La}$ & 2.57 & 2.44 & 2.22 & 2.16 \\
$\mathrm{Ce}$ & 2.56 & 2.44 & 2.25 & 2.20 \\
$\mathrm{Pr}$ & 2.53 & 2.44 & 2.26 & 2.23 \\
$\mathrm{Nd}$ & 2.51 & 2.40 & 2.26 & 2.22 \\
$\mathrm{Sm}$ & 2.52 & 2.42 & 2.30 & 2.28 \\
$\mathrm{Eu}$ & 2.54 & 2.46 & 2.31 & 2.25 \\
$\mathrm{Gd}$ & 2.54 & 2.45 & 2.31 & 2.23 \\
$\mathrm{~Tb}$ & 2.59 & 2.45 & 2.34 & 2.30 \\
$\mathrm{Dy}$ & 2.59 & 2.48 & 2.37 & 2.37 \\
$\mathrm{Ho}$ & 2.60 & 2.45 & 2.39 & 2.38 \\
$\mathrm{Er}$ & & 2.47 & 2.41 & 2.41 \\
$\mathrm{Tm}$ & 2.64 & 2.51 & 2.46 & 2.46 \\
$\mathrm{Yb}$ & & 2.51 & 2.47 & 2.44 \\
$\mathrm{Lu}$ & 2.67 & 2.54 & 2.50 & 2.48 \\
$\mathrm{La} / \mathrm{Sm}$ & 1.02 & 1.01 & 0.97 & 0.95 \\
$\mathrm{Gd} / \mathrm{Yb}$ & & 0.98 & 0.94 & 0.91 \\
\hline
\end{tabular}

Table 4 